\title{
PRELIMINARY STUDY OF THE IONOSPHERE RESPONSE TO THE GEOMAGNETIC STORM OCCURRED ON SEPTEMBER 26, 2011
}

\author{
Emília Correia ${ }^{1,2, *} \&$ Amanda Junqueira Paz ${ }^{2}$ \\ 'Instituto Nacional de Pesquisas Espaciais, São José dos Campos, SP, Brazil \\ ${ }^{2}$ Centro de Rádio Astronomia e Astrofísica Mackenzie, Escola de Engenharia, Universidade Presbiteriana Mackenzie, \\ Rua da Consolação 930, Ed. Modesto Carvalhosa $7^{\circ}$ andar, CEP 01302-907, São Paulo, SP, Brazil \\ *e-mail: ecorreia@craam.mackenzie.br
}

Abstract: Geomagnetic storms generate disturbances in the ionosphere due to the incidence of energetic particles, which can disturb communication and navigation systems. To understand the phenomena we analyzed ionosonde and GPS data obtained at Comandante Ferraz Brazilian Antarctic Station $\left(62.1^{\circ} \mathrm{S}, 58.4^{\circ} \mathrm{W}\right)$ and studied the effect produced by a geomagnetic storm that occurred on $26^{\text {th }}$ September 2011. The analysis covers the period of 24-30 September when the effect of the moderate geomagnetic storm produced an electron density increase in the ionospheric $F$ region.

Keywords: Ionosphere; Ionosonde; GPS; Geomagnetic Storm

\section{Introduction}

Geomagnetic storms are produced when Coronal Mass Ejection (CME) reach the Earth's magnetosphere in association with magnetic field reconnection. During geomagnetic storms energetic particles penetrate the magnetosphere, follow the magnetic field lines and precipitate in the polar region. This particle precipitation increases the electron density in the ionosphere and can be detected as ionospheric perturbations by radio sounding techniques such as ionosonde and GPS.

Here we present the ionospheric disturbance produced by the geomagnetic storm that occurred on September 26, 2011. The preliminary results are discussed in continuity, considering the VTEC variations and foF 2 and h'F parameters, which are compared with the geomagnetic index Dst.

\section{Materials and Methods}

To analyze the effect of geomagnetic storm on the ionosphere, we used different types of data:

- The Total Electron Content (TEC) of the ionosphere was obtained using a dual frequency GPS receiver operating at EACF. By the delay between the two frequencies of radio wave reception coming from the satellite to the receiver it is possible estimate the total electron content (TEC). The TEC was obtained every second using the routine La Plata Ionospheric Model (LPIM) developed at the University of La Plata (Brunini et al., 2008). The analysis considers the vertical TEC (VTEC), which is the TEC correct by the zenithal angle at about $300 \mathrm{~km}$ high. (TECU is TEC unit $=10^{16}$ electron $/ \mathrm{m}^{2}$ column density).

- The parameters foF2 and h'F were obtained using a CADI ionosonde operating at EACF. The parameter foF2 refers to the F2-layer vertical incidence critical frequency $(\mathrm{MHz})$ and h'F $(\mathrm{km})$ is the F layer bottom height. They were obtained from ionograms performed every 5 minutes. The software used for data reduction is the UNIVAP Ionosonde Digital Data Analysis (UDIDA), developed at the University of the Vale do Paraíba (Fagundes et al., 2005).

- The DST (disturbance storm time) is the geomagnetic index that measures the equatorial surface magnetic field variations and gives information about the intensity of the geomagnetic storm. This data was obtained at the site 
of the World Data Centre for Geomagnetism (WDC-C2) (http://wdc.kugi.kyoto-u.ac.jp/dstae/index.html)

\section{Results}

The analysis of ionosphere parameters variations associated with the moderated geomagnetic storm ( - $100 \mathrm{nT}$ ) ocurred on September 26 were evaluated during the period of 24 30 September, considering September 23 as the quiet day.

Figure 1 shows that foF 2 increased about $40 \%$ above the quiet conditions during the main phase of the geomagnetic storm. This density increase was accompanied by $\sim 50 \mathrm{~km}$ increase in height of the F2 layer (h'F). Both parameters returned to the quiet level during the geomagnetic recovery phase.

The VTEC (Figure 2) also shows a strong increase of almost three times above the quiet level during the main phase of the geomagnetic storm, practically returning to quiet level during next day time, but suggesting depletion in the two next nights during the recovery phase.

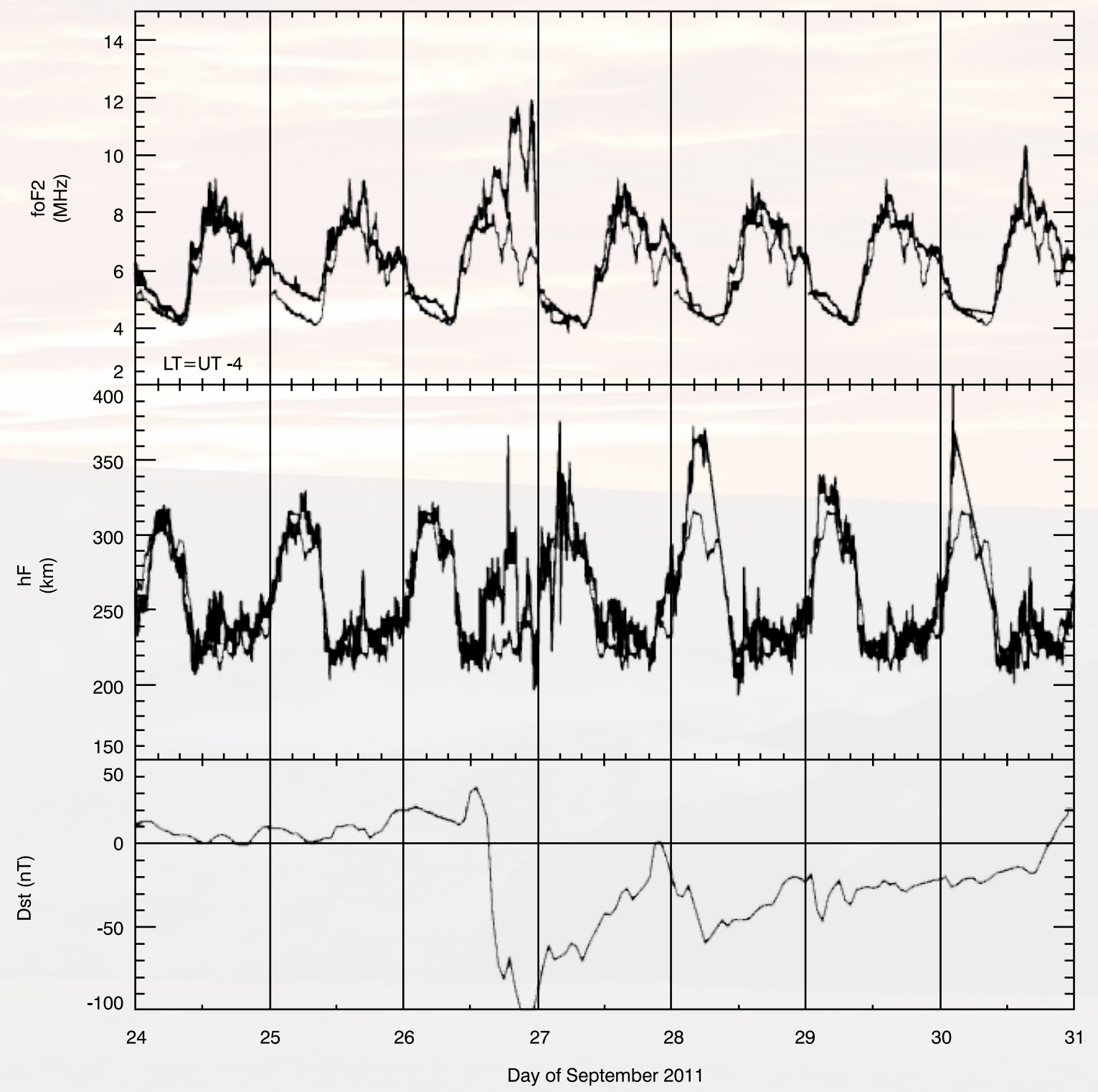

Figure 1. foF2 and h'F ionosphere parameter variations compared with DST index from 24 to 30 September 2011. 


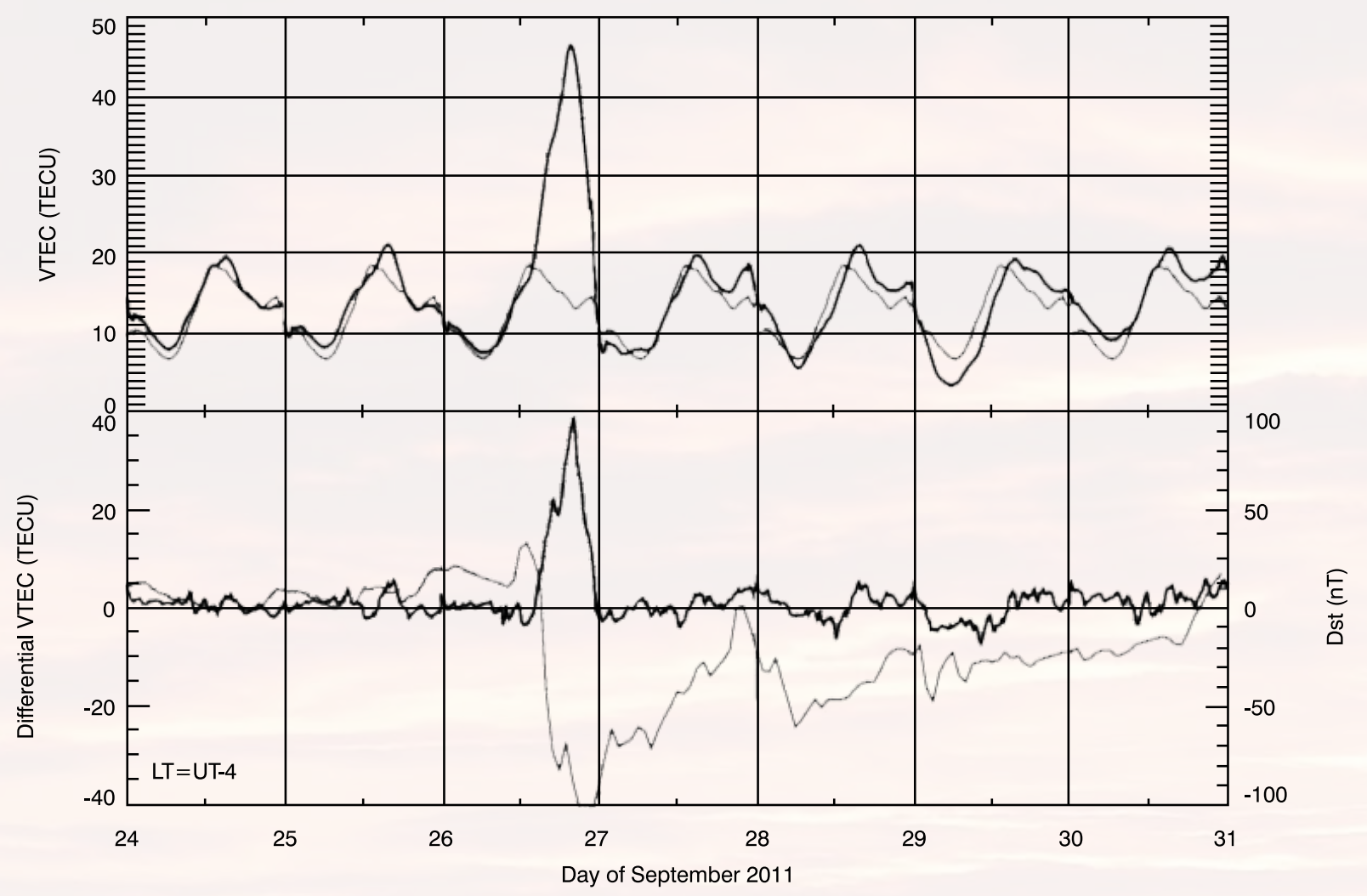

Figure 2. VTEC and differential variation between 24 and 30 September 2011 compared with Dst index

\section{Discussion}

The evaluation of a moderate geomagnetic storm (-100 nT) impact in the ionosphere at mid-latitude (EACF) was studied considering VTEC (GPS), foF2 and h'F (ionosonde) parameters, which give information about F-region ionosphere storm response.

The VTEC and foF2 show a positive ionospheric storm response during the main phase of the geomagnetic activity that occurred in the local afternoon sector, which means an increase of ionization density. This was accompanied by a significant increase in the height of the F2 layer as showed by the h'F parameter.

The positive ionospheric storm response has been reported as typical at middle latitudes (e.g. Mendillo, 2006; Prolss, 2008). The possible more important mechanisms to account this ionospheric behavior are the equatorward winds and eastward-directed electric fields (Cander, 2007; Prolss, 2008). In the case of equatorward winds, the field- aligned component of the frictional force between the ions and electrons will push the ionization up following the magnetic field lines. The particle motion results in the uplifting of the F2 layer, which increases the ionization density during daytime. In the case of electric field mechanism the height increase is caused by an EX $B$ drift, which is followed by a poleward drift.

VTEC measurements show negative values in the next two nights after the main phase of the geomagnetic storm. This behavior at mid-latitudes has been explained by changes in the neutral atmosphere as consequence of Joule heating in the auroral thermosphere, which expands the thermosphere and enhance the effective electron loss rate (e.g. Danilov \& Lastovicka, 2001; Mendillo, 2006).

\section{Conclusion}

The moderate geomagnetic storm that occurred on September 26, 2011 presented a sudden commencement 
at around 12:00UT, and its main phase started at 14:00UT with minimum Dst of about -100 nT at 23:00 UT. The VTEC and foF 2 show strong increase during the main phase of the geomagnetic storm, which was accompanied by an uplifting of the F2 layer in the ionosphere. The ionospheric ionization density increases have been reported as typical when main phase of geomagnetic storms occur in the local afternoon time at middle latitudes. This ionospheric behavior has been mostly explained considering equatorward winds as well as to eastward electric field mechanisms. But independently of the mechanism is operating there are still open questions about the origin of the winds and/or electric fields. Thus, the positive ionospheric storms at middle latitudes is a phenomenon not well understood yet, and deserves special attention from observations at different latitudes and longitudes.

\section{Acknowledgments}

This work integrates the National Institute of Science and Technology Antarctic Environmental Research (INCTAPA) that receives scientific and financial support from the National Council for Research and Development (CNPq process: $n^{\circ}$ 574018/2008-5) and Carlos Chagas Research Support Foundation of the State of Rio de Janeiro (FAPERJ $n^{\circ}$ E-16/170.023/2008). The authors also acknowledge the support of the Brazilian Ministries of Science, Technology and Innovation (MCTI), of Environment (MMA) and InterMinistry Commission for Sea Resources (CIRM). EC also thanks $\mathrm{CNPq}$ for individual research support (processes no.: 52.0186/06-0, 556872/2009-6, 163576/2012-2) and the National Institute for Space Research (INPE/MCTI).

\section{References}

Brunini, C., Meza A., Gende, M., \& Azpilicueta F. (2008). South American regional ionospheric maps computed by GESA: a pilot service in the framework of SIRGAS. Advances in Space Research, 42, 737-44. http://dx.doi.org/10.1016/j.asr.2007.08.041

Cander, L. R. (2007). Spatial correlation of foF2 and vTEC under quiet and disturbed ionospheric conditions: case study. Acta Geophysica, 55(3), 410-23. http://dx.doi.org/10.2478/s11600-007-0011-9

Danilov, A. D., \& Lastovicka, J. (2001). Effects of geomagnetic storms on the ionosphere and atmosphere. International Journal of Geomagnetic Aeronomy, 2, 209-224.

Fagundes, P. R., Pillat, V. G., Bolzan, M. J. A., Sahai, Y., Becker-Guedes, F., Abalde, J. R. et al. (2005). Observations of F-layer electron density profiles modulated by pw type oscillations in the equatorial ionospheric anomaly region. Journal of Geophysical Research, 110(A12302), 1-8.

Mendillo, M. (2006). Storms in the ionosphere: Patterns and processes for total electron content. Reviews of Geophysics, 44(RG 4001), 1-47. http://dx.doi.org/10.1029/2005RG000193

Prolss, G. W. (2008). Ionospheric storms at mid-latitude: a short review. In P. M. Kintner, A. J. Coster, T. Fuller-Rowell, A. J. Mannucci, M. Mendillo \& R. Heelis (Eds.), Midlatitude ionospheric dynamics and disturbances (Geophysical Monograph Series, Vol. 181, pp. 9-24). Washington: American Geophysical Union. http://dx.doi.org/10.1029/181GM03 